\title{
Sporulation in Protoplasts of the Yeast, Saccharomyces cerevisiae
}

\author{
By MARIE KOPECKÁ \\ Department of General Biology, Faculty of Medicine \\ $J$ E. Purkyně University, Brno, Czechoslovakia \\ (Received 7 January 1974: revised 19 February 1974)
}

\begin{abstract}
SU M M A R Y
Protoplasts of Saccharomyces cerevisiae cultivated in sporulation medium with an osmotic stabilizer at $\mathrm{pH} 7.0$ were studied by means of light and electron microscopy. After I $5 \mathrm{~h}$, mature ascospores with complete cell walls were formed in the protoplasts. During sporulation, protoplasts regenerated only the fibrillar wall component and were osmotically sensitive. By using snail enzymes to block fibril regeneration on the protoplast surface, it was proved that sporulation was quite independent of such regeneration. Most of the ascospores produced by protoplasts were viable, osmotically resistant and gave rise to new yeast cells. Meiotic division and sporulation in the yeasts are processes quite independent of the presence of the ascus wall.
\end{abstract}

\section{INTRODUCTION}

Protoplasts have been prepared from bacteria, blue-green and green algae, moulds, yeasts and from a number of meristematic cells of higher plants. For all the investigated species except blue-green algae, conditions facilitating regeneration of the cell wall have been found (for review see Gabriel, I973).

Protoplasts of bacteria, yeasts, moulds and green algae with incomplete walls cannot undergo cell division, even though nuclear division occurs, and consequently they die (for review see Nečas, 197I). However, another way in which protoplasts of yeasts and bacteria can survive is by sporulation (Salton, 1955; Eddy \& Williamson, I959; Fitz-James, I964; Stárka \& Č́slavská, 1964).

This study was conducted in an attempt to investigate: (i) the process of sporulation in yeast protoplasts, both qualitatively and quantitatively, by means of light and electron microscopy; (ii) whether meiotic division and sporulation of the protoplasts are dependent on ascus wall regeneration; (iii) whether spores formed by protoplasts are viable and can give rise to new yeasts.

\section{METHODS}

Organism. Saccharomyces cerevisiae, laboratory strain No. 7, was used throughout the experiments.

Preparation of protoplasts. Yeasts from the stock culture were inoculated into ro ml malt-extract-wort medium, $\mathrm{pH} 5.5$, and incubated at $28{ }^{\circ} \mathrm{C}$ without shaking. After approximately $30 \mathrm{~h}$, yeast cultures were near the end of the log phase of growth and were ready for the preparation of protoplasts by the use of snail enzymes as described by Eddy \& Williamson (I957). Fresh protoplasts were washed three times with McIlvaine citrate-phosphate buffer, $\mathrm{pH} 5.5$, with $0.6 \mathrm{M}-\mathrm{KCl}$ and $0.0 \mathrm{I} \mathrm{M}-\mathrm{MgSO}_{4}$ added to the buffer.

Sporulation of protoplasts. Fresh protoplasts were transferred to the sporulation medium 
with an osmotic stabilizer $(0.5 \%, \mathrm{w} / \mathrm{v}$, potassium acetate and $4.5 \%$, w/v, potassium chloride in Sörensen phosphate buffer, $\mathrm{pH}_{7}^{\circ} \mathrm{O}$ ) to give a concentration of about $\mathrm{I} \cdot 0 \times 10^{7}$ to $2.0 \times 10^{7} / \mathrm{ml}$ medium (Fowell, I969). Incubation was carried out either in liquid sporulation medium shaken $(100 \mathrm{rev} . / \mathrm{min})$ at $28{ }^{\circ} \mathrm{C}$ or on the surface of $\mathrm{I} .5 \%(\mathrm{w} / \mathrm{v})$ agar sporulation medium with a given concentration of protoplasts spread over the agar surface. Sporulating protoplasts were observed by phase-contrast microscopy.

To determine the ability of growing protoplasts to sporulate, fresh protoplasts were grown either in malt extract wort at $\mathrm{pH} 5.5$ or in acetate pre-sporulation growth medium (Roth \& Halvorson, I969) to which osmotic stabilizer $(4.5 \%$, w/v, potassium chloride) was added. After growth for about $30 \mathrm{~h}$, protoplasts were washed three times with fresh sporulation medium and the washings were cultivated on a shaker, as mentioned above.

In order to determine whether sporulation and wall regeneration were independent processes protoplasts were cultivated in the sporulation medium supplemented by snail digestive juice: fresh crude juice from snail (Helix pomatia) stomach was evaporated and frozen in a refrigerator at $0{ }^{\circ} \mathrm{C}$ and used at $\mathrm{I} \cdot 0 \%(\mathrm{w} / \mathrm{v})$, a concentration which is known to block wall regeneration in yeast protoplasts (Kopecká, Čtvrtníček \& Nečas, I965) but not to affect ascospores (Johnson \& Mortimer, 1959).

Bacterial contamination was prevented by the addition of $10 \mu \mathrm{g}$ Tetracyklin Spofa (United Pharmacological Works, Prague) per ml sporulation medium.

Electron microscopy. The ultrastructure of sporulating protoplasts was studied by means of a freeze-etching technique. The sporulating protoplasts were frozen either directly in the sporulation medium or after $\mathrm{I} 2 \mathrm{~h}$ incubation in $20 \%(\mathrm{w} / \mathrm{v})$ glycerol at $4{ }^{\circ} \mathrm{C}$, and freezeetched in an apparatus (Balzer) by Moor \& Mühlethaler's (I963) method. The replicas were washed with sulphuric acid and Eau de Javelle as described by Moor \& Mühlethaler (1963) and then subjected to a $40 \%$ chromic acid treatment (R. Janisch, personal communication).

Synthesis of the fibrillar wall component in sporulating protoplasts was observed on preparations shadowed with platinum and carbon. Living protoplasts collected at various times of cultivation in sporulation medium were placed on Formvar-coated grids and allowed to dry. The dried preparations were washed two or three times with distilled water and, after drying, shadowed with platinum and carbon. The preparations were examined with a Tesla BS 242 electron microscope.

Viability of ascospores produced by protoplasts. Protoplasts cultivated in sporulation medium were collected by centrifugation and washed three times with distilled water. Distilled water was added to the pellet to achieve immediate lysis of protoplasts and release of ascospores, which were then inoculated at $\mathrm{I} \cdot 0 \times 10^{7} / \mathrm{ml}$ on to the surface of $2.0 \%$ malt-extract-wort agar or into liquid malt extract wort without an osmotic stabilizer, and incubated on a shaker. They were examined by means of phase-contrast microscopy and freeze-etching techniques.

\section{RESULTS}

Sporulation of protoplasts. The rate of ascospore formation in the protoplasts was the same as that in normal yeasts. In the fresh protoplasts, or those cultivated in liquid sporulation medium for ro h, no ascospores could be found (Figs. I, 2 and 6). After incubation of $20 \mathrm{~h}$ about $45 \%$ of the protoplasts formed ascospores (Fig. 3). Such a culture consisted of a mixture of ascospores (either liberated from or still inside protoplasts) and vacuolated protoplasts in different stages of ascospore formation, but without visible ascospores. After $30 \mathrm{~h}$ incubation the number of sporulating protoplasts had increased to $73 \%$. 
Following sporulation, the ascospores can be liberated from protoplasts by osmotic stress with distilled water and separated from protoplast ghosts by centrifugation (Fig. 4). The liberated ascospores were osmotically resistant and remained associated in groups of four (Fig. 4). Figure 5 shows the arrangement of ascospores in normal sporulating yeast. The maximum yield of four-spored clusters in the protoplast culture approached $60 \%$; the remaining protoplasts produced only I, 2 or 3 ascospores per protoplast. These results corresponded to those in normal yeasts of our strain.

Protoplasts sporulated much better in liquid sporulation medium than on agar, where sporulation was slower and resulted in production of fewer ascospores. This observation agrees with the findings of other authors working with intact organisms (for review see Fowell, 1969).

Neither regeneration of rigid wall on the protoplast surface nor reversion of protoplasts was observed during sporulation.

Electron microscopy of sporulating protoplasts. In contrast to fresh protoplasts, protoplasts after $\mathrm{Io} \mathrm{h}$ of incubation in sporulation medium contained numerous mitochondria, lipid vesicles and smaller vacuoles, and were rich in the cisternae of endoplasmic reticulum, often arranged in a parallel array (Fig. 6). Occasionally, meiotic division of nuclei was observed. After $20 \mathrm{~h}$ ascospores were found in protoplasts (Fig. 7). These ascospores contained the structures characteristic of normal yeast ascospores (Guth, Hashimoto \& Conti, 1972). During sporulation the fibrillar component of the wall regenerated on the surface of the protoplasts (Fig. 8). The mature ascospores liberated from protoplasts could be seen inside fibrillar nets (Fig. 9).

Sporulation in growing protoplasts. Protoplasts grown previously for about $30 \mathrm{~h}$ in liquid nutrient medium with glucose, and which showed nuclear division and regeneration of fibrillar wall components on the protoplast surfaces (Nečas, 1956; Kopecká et al. I965; Kopecká, Nečas \& Svoboda, 1970), were subsequently transferred to sporulation medium. After transfer, even such pre-grown multinucleate protoplasts were able to sporulate and the dynamics of ascospore formation was similar to that of the fresh protoplasts. Liberated ascospores remained caught within clearly visible dense fibrillar nets (Fig. Io).

Sporulation of protoplasts in the presence of snail enzymes. It is apparent from the above that protoplasts can regenerate the fibrillar component of the wall in sporulation medium. To determine whether protoplast wall-synthesis and sporulation were processes dependent upon each other, we studied sporulation in protoplasts in which regeneration of the fibrillar wall component was blocked by snail enzymes. Even under these conditions the protoplasts formed ascospores.

Germination of ascospores produced by protoplasts. When liberated ascospores were inoculated onto the surface of malt-extract-wort agar about $90 \%$ of ascospores formed microcolonies of yeast. When inoculated into liquid malt extract the ascospores increased in size, but for the first 2 to $3 \mathrm{~h}$ their contents remained homogeneous. Afterwards, vacuoles appeared and buds were formed (Fig. II). When cultivated on a shaker, germinating ascospores formed zygotes which gave rise to new yeast cells by budding (Fig. 12).

Electron microscopy of germinating ascospores showed the same organelles as in mature yeast cells (Moor \& Mühlethaler, 1963) and the process of budding was analogous to that found in the budding yeast (Moor, 1967). 

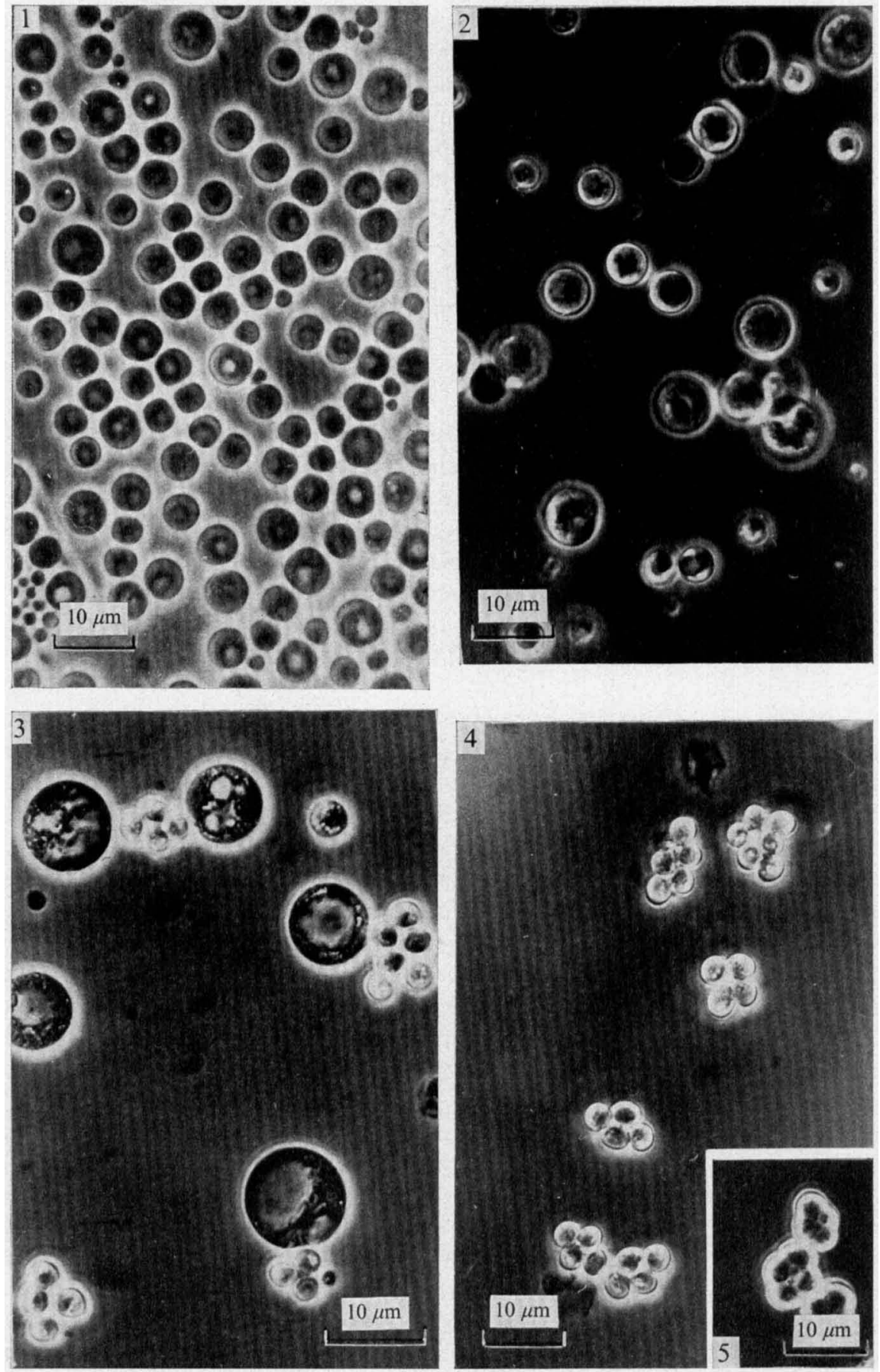

Fig. I. Protoplasts of $S$. cerevisiae prepared by $2 \mathrm{~h}$ digestion with snail enzymes in $0.6 \mathrm{M}-\mathrm{KCl}$ $(\mathrm{pH} 5.5)$ at $28^{\circ} \mathrm{C}$ on a shaker. Vacuoles are visible in the protoplasts.

Fig. 2. Protoplasts of $S$. cerevisiae cultivated in sporulation medium for $10 \mathrm{~h}$. Vacuoles have disappeared in most protoplasts but no ascospores are yet present.

Fig. 3. Protoplasts of $S$. cerevisiae cultivated in sporulation medium for $20 \mathrm{~h}$, showing vacuolated spherical sporulating protoplasts and mature liberated ascospores in four-spore clusters.

Fig. 4. Free ascospores, without the ascus wall, of $S$. cerevisiae, separated from protoplasts by osmotic stress with distilled water and by centrifugation.

Fig. 5. Ascospores produced by normal sporulating cells of S. cerevisiae. Ascospores are enclosed in the ascus. 

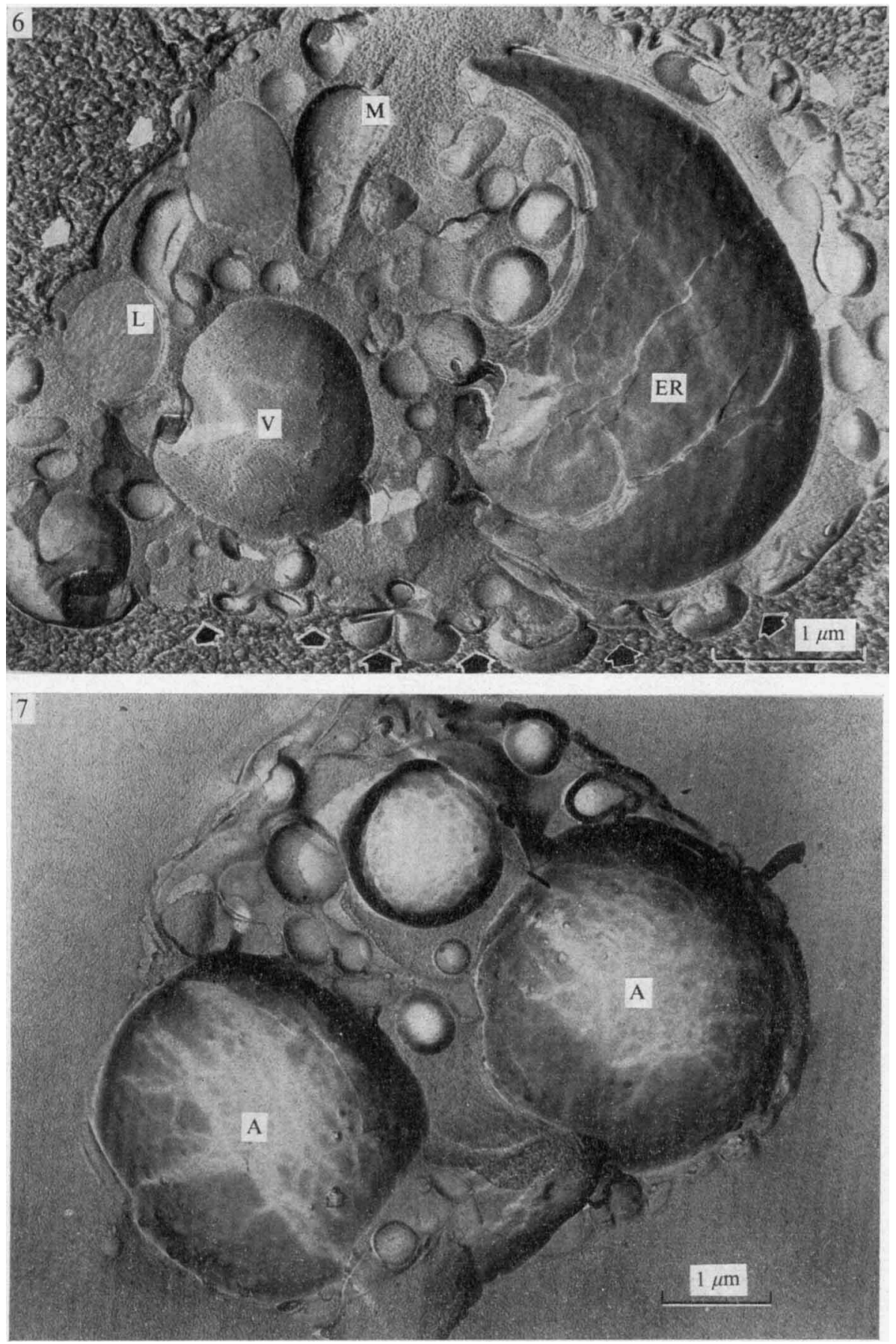

Fig. 6. Electron micrograph of freeze-etched sporulating protoplast of $S$. cerevisiae after io $\mathrm{h}$ in sporulation medium shows many mitochondria, lipid granules, smaller vacuoles and parallel cisternae of endoplasmic reticulum. In the plasma membrane deep invaginations were found (arrowed) caused by the treatment of protoplasts with $20 \%$ glycerol (Kopecká, Svoboda \& Brichta, 1973). ER, Endoplasmic reticulum; M, mitochondrion; L, lipid granules; V, vacuole.

Fig. 7. Electron micrograph of a freeze-etched sporulating protoplast of S. cerevisiae after $20 \mathrm{~h}$ incubation in sporulation medium. Two ascospores are visible inside the protoplast. Treated with $20 \%$ glycerol before freeze-etching. A, Ascospore. 

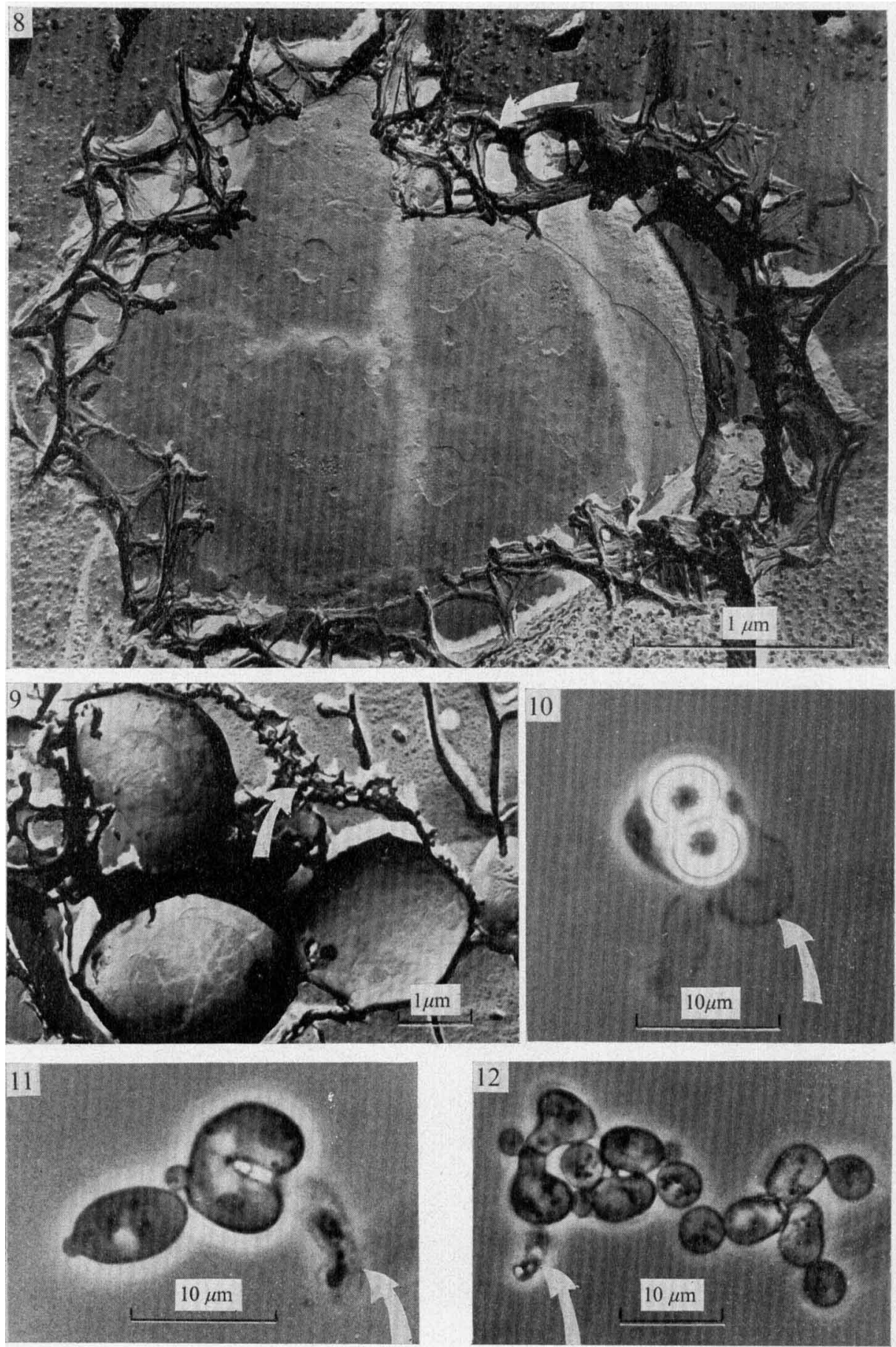


\section{DISCUSSION}

The above results show that protoplasts of the yeast Saccharomyces cerevisiae sporulated when cultivated in $0.5 \%(\mathrm{w} / \mathrm{v})$ potassium acetate with $4.5 \%(\mathrm{w} / \mathrm{v})$ potassium chloride at $\mathrm{pH} 7{ }^{\circ}$. This finding is in agreement with the results of Eddy \& Williamson (I959) who observed the sporulation of protoplasts of the yeasts Saccharomyces carlsbergensis in a complex synthetic medium without any source of nitrogen.

Conclusive evidence was obtained that the ascospores occurring among protoplasts in sporulation medium arose from the protoplasts and not from the normal cells occasionally present among protoplasts: (i) the number of living cells among protoplasts in our experiments did not exceed $\mathrm{I} \cdot 0 \%$; (ii) the fresh sporulating protoplasts remained spherical during the whole sporulation process, while the normal cells were oval; (iii) ascospores inside the protoplasts were observed by both phase-contrast and electron microscopy; (iv) the ascospores formed by protoplasts were free of the ascus wall, while ascospores produced by normal cells were enclosed by the ascus (see Figs. 4 and 5); (iv) the most conclusive evidence of protoplast sporogenesis was provided by observations with the electron microscope of the ascospores enclosed in the fibrillar wall component, a structure formed exclusively by protoplasts in liquid media (Kopecká et al. 1970).

In all the cultures tested, sporulation occurred more frequently with protoplasts harvested at the end of the exponential phase of growth than with those from the early exponential and stationary growth phases, with which lysis often occurred. The osmotic stabilizers tested were $0.6 \mathrm{M}$-potassium chloride, $0.6 \mathrm{M}$-sodium chloride, $0.7 \mathrm{M}$-mannitol and $0.7 \mathrm{M}$ rhamnose, of which potassium chloride stabilizer was the most suitable. For sporulation of protoplasts $\mathrm{pH} 7.0$ was used, because between $\mathrm{pH} 8.0$ and 10.0 immediate lysis of protoplasts occurred. About $70 \%$ of the protoplasts sporulated. This finding corresponds to the number of cells sporulating in normal cultures of our strain. Most of the spores produced by protoplasts were viable.

The fact that in liquid medium protoplasts cannot produce rigid cell walls (except for the fibrillar component) yet can build the complete wall of the ascospore inside the protoplast, is apparently connected with the removal of wall components and wall-synthesizing enzymes from the protoplast surface by the liquid medium (for reviews see Nečas, I97I ; Kreger \& Kopecká, 1973).

The ability of sporulating protoplasts to regenerate the fibrillar wall component raised the question of whether the two processes were independent of each other. By blocking the regeneration of the fibrillar wall component with snail enzymes during sporulation it was proved that sporulation occurred quite independently of wall regeneration. The two pro-

Fig. 8. Electron micrograph of freeze-etched $S$. cerevisiae protoplast after $30 \mathrm{~h}$ on sporulation medium, showing fibrillar wall component (arrowed) on the spore surface.

Fig. 9. Electron micrograph of three freeze-etched spores formed by one S. cerevisiae protoplast and enclosed inside the same fibrillar component (shown by arrow).

Fig. 10. Two spores which were produced by one growing yeast protoplast of $S$. cerevisiae. Spores are enclosed in the fibrillar component of the wall (arrowed).

Fig. I I. Germinating ascospores of $S$. cerevisiae which were produced by a growing protoplast, and which are enclosed in a fibrillar net (arrowed).

Fig. 12. Shake culture of germinating ascospores of $S$. cerevisiae which have formed zygotes in malt-extract-wort medium. Germinating spores and zygotes (enclosed in a fibrillar net - arrowed) have given rise to new yeast cells by budding. 
cesses are probably controlled by different mechanisms. This is unlike the sporulation in bacterial protoplasts, in which the sporogenesis needs to be induced before the bacterial cell is converted to a protoplast (Salton, I955; Fitz-James, I964; Stárka \& Čáslavská, 1964).

Concerning the relationship between nuclear and cell division in yeast protoplasts, it seems that the triggering of both the mitotic (Nečas, 1956) and meiotic nuclear divisions is not dependent on the wall present on the protoplast surface. However, vegetative division of the whole protoplast cannot occur in the absence of the complete cell wall around the protoplast. In contrast, division of the protoplast after meiosis is triggered without a wall (ascus) on the protoplast surface. It can therefore be presumed that the two types of cytokinesis are controlled by different mechanisms.

The author thanks Dr M. Gabriel and Dr N. J. W. Kreger-van Rij for useful discussions, and Professor O. Nečas for critically reading the manuscript.

\section{REFERENCES}

EDDY, A. A. \& Williamson, D. H. (I957). A method of isolating protoplasts from yeasts. Nature, London I79, $1252-1253$.

Eddy, A. A. \& Williamson, D. H. (1959). Formation of aberrant cell walls and of spores by the growing yeast protoplasts. Nature, London $\mathbf{1 8 3}$, I IOI-I I04.

Firz-JAMES, F. P. (1964). Sporulation in protoplasts and its dependence on prior forespore development. Journal of Bacteriology 87, 667-675.

Fowell, R. P. (1969). Sporulation and hybridization of yeasts. In The Yeasts, vol. I, pp. 303-383. Edited by A. H. Rose and J. S. Harrison. London and New York: Academic Press.

GABRIEL, M. (1973). Regeneration of protoplasts of lower plant cells. Ph.D. thesis, J. E. Purkyně University, Brno.

Guth, E., Hashimoto, T. \& Contı, S. F. (1972). Morphogenesis of ascospore in Saccharomyces cerevisiae. Journal of Bacteriology 98, 869-880.

Johnson, J. R. \& Mortimer, R. K. (I959). Use of snail digestive juice in isolation of yeast spore tetrads. Journal of Bacteriology 78, 292-299.

KOPECKÁ, M., ČTVRTNíČEK, O. \& NeČAS, O. (1965). Formation and properties of fibrillar network formed in yeast protoplasts as the first step of biosynthesis of cell wall. In Symposium über Hefe-Protoplasten, pp. 73-75. Edited by R. Müller. Berlin: Akademie Verlag.

KopeCKÁ, M., NeČAS, O. \& SVOBOda, A. (1970). Structure and formation of the fibrillar component of the growing cell walls in yeast protoplasts. In Yeast Protoplasts. Proceedings of the International Symposium, pp. 197-201. Edited by O. Nečas and A. Svoboda. Brno: J. E. Purkyně University Press.

KopeckÁ, M., Svoboda, A. \& Brichta, J. (1973). Effect of 'osmotic stabilizers' and glycerol on yeast cell envelopes. Zeitschrift für allgemeine Microbiologie $\mathbf{1 3}_{3}, 48 \mathrm{I}-487$.

KREGER, D. R. \& KopeckÁ, M. (1973). On the nature of the fibrillar nets formed by protoplasts of Saccharomyces cerevisiae in liquid media. In Yeast, Mould and Plant Protoplasts. Proceedings of Third International Symposium, Salamance. London: Academic Press.

Moor, H. (1967). Endoplasmic reticulum as the initiator of bud formation in yeast. Archiv fïr Mikrobiologie 57, I35-146.

MOOR, H. \& MüHLETHALER, K. (1963). Fine structure in frozen-etched yeast cells. Journal of Cell Biology $\mathbf{1} 7$, 609-628.

NeČAS, O. (1956). Vitality of cell fragments of yeasts. Relation of the nucleus to the growth ability. Folia microbiologica (Praha) 2, 29-35.

NEČAS, O. (197I). Cell wall synthesis in yeast protoplasts. Bacteriological Reviews 35, 149-170.

Roth, R. \& Halvorson, H. O. (I969). Sporulation of yeast harvested during logarithmic growth. Journal of Bacteriology 98, 83I-832.

Salton, M. R. J. (1955). Formation of spores in protoplasts of Bacillus megatherium. Journal of General Microbiology I3, iv-v.

Stárka, J. \& Č́̉slavskÁ, J. (1964). Sporulation of bacterial protoplasts. Folia microbiologica (Praha) 9 , 2 I-23. 